\title{
AGPAT6 gene EX1_303T > C and EX12_299G > A mutations and associations with economic traits of Chinese Simmental-cross cattle
}

\author{
Xiaojuan Long, Xibi Fang, Ping Jiang, Hang Xiao, Haibin Yu, Mengjiao Zhou, Yunzhi Pan, \\ Chunyan Lu, Zhihui Zhao, and Runjun Yang \\ College of Animal Science, Jilin University, Xi’An Road 5333, Changchun, Jilin 130062, China
}

Correspondence to: Runjun Yang (yrj@jlu.edu.cn)

Received: 23 March 2016 - Revised: 25 May 2016 - Accepted: 7 June 2016 - Published: 21 June 2016

\begin{abstract}
One of the 11 members in the family of 1-acylglycerol-3-phosphate-O- acyltransferases (AGPATs), $A G P A T 6$, is responsible for the second step in the biosynthesis of triacylglycerol in eukaryotes. The AGPAT6 gene is highly expressed in brown adipose tissue, mammary gland epithelial cells and many other tissues. In this study, the PCR-restriction fragment length polymorphism technique was applied to detect sites of polymorphism in the bovine AGPAT6 gene, and two single nucleotide polymorphisms (SNPs) were detected in the exon 1 and exon 12. Thirty-three traits associated with the meat quality and the carcass were also measured in Chinese Simmentalcross steers. The association between the two SNPs and the traits was then analyzed. The polymorphism site EX1_303T > C was significantly associated with the omasum weight, liver weight, $\mathrm{pH}$ value of the beef (carcass), fat coverage rate of the carcass, fat color score, kidney weight and back fat thickness. The polymorphism site EX12_299G > A was significantly associated with bone net weight, forehoof weight, hind feet weight, the fat coverage rate of the carcass, the head and heart weight and the marbling score. Thus, the polymorphisms in the AGPAT6 gene might be important genetic factors that influence the carcass yield and meat quality of beef cattle and may be useful markers of meat quality traits in future marker-assisted selection programs for the breeding and production of beef cattle.
\end{abstract}

\section{Introduction}

In eukaryotes, the two major pathways for the biosynthesis of triacylglycerol (TG) are the monoacyglycerol and the glycerol phosphate pathways. The glycerol phosphate pathway is the primary pathway used in most cell types (Takeuchi and Reue, 2009; Ye et al., 2005), and 1-acylglycerol-3phosphate-O-acyltransferase (AGPAT), known as lysophosphatidic acid acyltransferase (LPAAT), is the crucial enzyme in the biosynthesis of TG for the second step of this pathway (Wendel et al., 2013). AGPAT transfers an additional fatty acid to the lysophosphatidic acid (LPA) at the sn-2 position of the glycerol backbone to produce phosphatidic acid (PA) (Prasad et al., 2011). Eleven members of the $A G P A T$ family have been described, and each member is encoded by a different gene (Eberhardt et al., 1997; Leung, 2001; Aguado and Campbell, 1998; Beigneux et al.,
2006; Agarwal et al., 2006, 2007; Agarwal and Garg, 2010; Sukumaran et al., 2009). The sequence homology indicates that AGPAT6 is one of 11 AGPAT isoforms (Nagle et al., 2008). However, the current study indicates that AGPAT6 is a novel microsomal glycerol-3-phosphate acyltransferase (GPAT), renamed GPAT4 (Chen et al., 2008). GPAT is the rate-limiting enzyme for the synthesis of TG and catalyzes the first step in its de novo synthesis (Chen et al., 2008; Gimeno and Cao, 2008; Gonzalez-Baro et al., 2007).

A study in mice showed that the AGPAT6 gene is highly expressed in brown adipose tissue, mammary gland epithelial cells and many other tissues and encodes the essential enzyme for the synthesis of milk fat (Beigneux et al., 2006; Liebisch et al., 2004). An AGPAT6 deficiency in mice resulted in resistance to diet-induced and genetic forms of obesity (Chen et al., 2008). Previous studies of AGPAT6 have primarily targeted milk quality and demonstrated that AGPAT6 
Table 1. Number of records, mean and standard deviations for traits included in the association analyses.

\begin{tabular}{|c|c|c|c|}
\hline Trait & $N$ & Mean & $\mathrm{SD}$ \\
\hline Carcass weight (kg) & 378 & 256.03 & 38.49 \\
\hline Dressing percentage $(\%)$ & 378 & 52.09 & 2.38 \\
\hline Net weight of bone $(\mathrm{kg})$ & 378 & 20.16 & 3.11 \\
\hline Hand weight $(\mathrm{kg})$ & 378 & 23.55 & 2.42 \\
\hline Forehoof weight (kg) & 378 & 5.92 & 0.69 \\
\hline Hind feet weight $(\mathrm{kg})$ & 378 & 3.50 & 1.03 \\
\hline Tare weight $(\mathrm{kg})$ & 378 & 42.36 & 6.26 \\
\hline $\begin{array}{l}\text { Rumen, reticulum and } \\
\text { abomasum weight }(\mathrm{kg})\end{array}$ & 378 & 7.53 & 0.94 \\
\hline Omasum weight $(\mathrm{kg})$ & 378 & 3.96 & 0.69 \\
\hline Heart weight $(\mathrm{kg})$ & 378 & 1.81 & 0.35 \\
\hline Liver weight (kg) & 378 & 5.88 & 1.11 \\
\hline $\begin{array}{l}\text { Lung and wind } \\
\text { pipe weight }(\mathrm{kg})\end{array}$ & 378 & 3.13 & 0.48 \\
\hline Kidney weight (kg) & 378 & 1.17 & 0.20 \\
\hline Kidney fat weight (kg) & 378 & 4.63 & 2.82 \\
\hline Testis weight $(\mathrm{kg})$ & 378 & 0.67 & 0.15 \\
\hline Genital fat weight $(\mathrm{kg})$ & 378 & 0.89 & 0.35 \\
\hline Spleen weight $(\mathrm{kg})$ & 378 & 0.85 & 0.18 \\
\hline Oxtail weight (kg) & 378 & 1.35 & 0.25 \\
\hline $\mathrm{pH}$ value of beef & 378 & 6.26 & 0.52 \\
\hline $\mathrm{pH}$ value after acid mature & 378 & 5.57 & 0.34 \\
\hline Carcass length $(\mathrm{cm})$ & 378 & 139.86 & 8.11 \\
\hline Carcass depth $(\mathrm{cm})$ & 378 & 64.47 & 3.27 \\
\hline Carcass brisket depth $(\mathrm{cm})$ & 378 & 65.33 & 3.63 \\
\hline Hind legs circumference $(\mathrm{cm})$ & 378 & 48.94 & 3.79 \\
\hline Hind legs width $(\mathrm{cm})$ & 378 & 44.63 & 2.65 \\
\hline Hind legs length $(\mathrm{cm})$ & 378 & 80.32 & 4.13 \\
\hline Thigh meat thickness $(\mathrm{cm})$ & 378 & 17.90 & 1.69 \\
\hline Thickness of loin $(\mathrm{cm})$ & 378 & 6.84 & 0.91 \\
\hline Back fat thickness (cm) & 378 & 0.95 & 0.63 \\
\hline $\begin{array}{l}\text { Fat coverage rate } \\
\text { of carcass }(\%)\end{array}$ & 378 & 48.16 & 21.58 \\
\hline Marbling score & 378 & 5.38 & 0.71 \\
\hline Rib eye area & 378 & 79.15 & 12.74 \\
\hline Muscle color score & 378 & 5.61 & 1.07 \\
\hline Fat color score & 378 & 2.72 & 0.97 \\
\hline
\end{tabular}

is significantly associated with milk yield and the protein and fat contents in milk (He et al., 2011). However, based on the regulatory effects of the AGPAT6 gene on the content of TG in adipose tissues and the liver, the AGPAT6 gene should be able to influence the meat quality and carcass traits of cattle.

Therefore, the objectives of this study were to detect SNPs of the AGPAT6 gene and to investigate the effects of SNPs on the meat quality and carcass traits in a population of Chinese Simmental-cross steers. The results of this study will provide useful evidence for the marker-assisted selection for the purebreeding and crossbreeding of beef cattle as well as for the preservation of important genetic resources in beef cattle.

\section{Materials and methods}

\subsection{Ethics statement}

The animal experiments were conducted in strict accordance with the guide for the care and use of laboratory animals prepared by the Jilin University Animal Care and Use committee (Permit number: SYXK (Ji) 2008-0010/0011). All standardized carcass and meat quality determinations were performed at the Chinese Academy of Agricultural Sciences Meat Laboratory.

\subsection{Materials}

The blood samples were obtained from 378 Chinese Simmental-cross steers ( 28 months old) that were provided by the Inner Mongolian Baolongshan cattle farm. Additionally, the cattle were randomly selected from two different Simmental-cross cattle populations. The blood samples $(10 \mathrm{~mL})$ were collected from the jugular veins with anticoagulant (acid citrate dextrose, ACD). The genomic DNA was isolated from the leukocytes with a DNA extraction kit (Tiangen, Beijing, China) following standard procedures, and the DNA was stored at $-80^{\circ}$.

\subsection{Traits analyzed}

The carcasses were stored in a refrigerated room between 0 and $4^{\circ}$ for $24 \mathrm{~h}$. All carcass and meat traits were measured based on criterion GB/T17238-2008 for the cutting standards of fresh and chilled beef in China (the Standards Press of China).

The final body weight and percentage of intramuscular fat (ultrasound determination) were recorded before slaughter. We recorded the traits listed below at the slaughterhouse. The yield grades for the carcasses were based on 13 carcass traits, and the quality grades for the meat were based on 6 meat quality traits. The carcass weight was the weight after the removal of all internal organs, the head and the inedible portions of the tail and legs. The carcass yield was calculated as follows: (hot-carcass weight $\times 100$ )/final weight. The weight of the kidney fat is expressed as both an absolute value and a percentage of the hot-carcass weight. The reported muscle $\mathrm{pH}$ (pH-STAR; Matthaus, Berlin, Germany) is the average of five measurements from five random positions on the freshly cut side of the first steak $24 \mathrm{~h}$ postmortem. The reported back fat thickness (measured with a caliper) is the average of two measurements. The degree of marbling is expressed as a percentage of the visible fat area on the total area of a steak that was sampled from the longissimus thoracis muscle (between the ninth and the tenth vertebrae). The rib eye area was measured with a plastic grid and is expressed as the cross-sectional area of the longissimus thoracis muscle between the tenth and eleventh ribs. The meat color (measured with an OPTO-STAR colorimeter) was assessed 
Table 2. The restriction enzyme as well as digestion reaction system of each SNP.

\begin{tabular}{lrrrrrrr}
\hline Polymorphism site & $10 \times$ buffer & DNA & Enzyme & $\mathrm{ddH}_{2} \mathrm{O}$ & Total & Temperature & Time \\
\hline EX1_303T $>$ C (BstNI) & $2 \mu \mathrm{L}$ & $10 \mu \mathrm{L}$ & $0.5 \mu \mathrm{L}$ & $7.5 \mu \mathrm{L}$ & $20 \mu \mathrm{L}$ & $60^{\circ}$ & $0.5 \mathrm{~h}$ \\
EX12_299G $>$ A (HhaI) & $2 \mu \mathrm{L}$ & $10 \mu \mathrm{L}$ & $0.5 \mu \mathrm{L}$ & $7.5 \mu \mathrm{L}$ & $20 \mu \mathrm{L}$ & $37^{\circ}$ & $4 \mathrm{~h}$ \\
\hline
\end{tabular}

on the rib eye (between the tenth and the eleventh ribs) after $1 \mathrm{~h}$ of blooming at $4^{\circ}$, and the mean value of three color measurements is reported. The fatty-acid composition was measured with the boron fluoride methanol method according to Monziois et al. (2007) The analysis was performed in accordance with the ISO 5509 (2000) norms and the AOAC procedures, and the results are expressed as grams per $100 \mathrm{~g}$ fresh tissue. Additionally, the bone, mesenteric fat, omental fat, carcass length, carcass depth, hind leg circumference, hind leg width, thigh meat thickness, fat coverage rate and fat color score were recorded at the slaughterhouse. To ensure the accuracy of weighing, the weighing of all samples followed the same standard, and every part was weighed by two researchers together. The number of records and the means of the analyzed traits are shown in Table 1.

\subsection{Primer and PCR amplification}

The primers were designed based on the published sequence of the bovine AGPAT6 gene (Ensembl accession number: ENSBTAG00000005730) with the program Primer Premier 5 , and two pairs of PCRs were designed to amplify the bovine AGPAT6 gene. The gene primer sequences are as follows: EX1-forward: TGGCAATGACAGACCTTCAGGAC, EX1-reverse: CAGGAGGCTGACAATCAGGCTGT; EX12forward: CACCTTGTGTCCCTTTCCGC, EX12-reverse: AGAACAGCACTCCCCTAGCCCT. PCR was performed in a total volume of $25 \mu \mathrm{L}$ of the following mixture: $100 \mathrm{ng}$ bovine genomic DNA, $0.2 \mu \mathrm{M}$ of each primer, $12.5 \mu \mathrm{L}$ $2 \times$ PCR Master Mix and $\mathrm{ddH}_{2} \mathrm{O}$. The PCR reaction system for the two SNPs was first incubated at $95^{\circ}$ for $5 \mathrm{~min}$, followed by 30 cycles at $95^{\circ}$ for $30 \mathrm{~s}, 61^{\circ}$ for $45 \mathrm{~s}$ and $72^{\circ}$ for $45 \mathrm{~s}$, with a final extension step at $72^{\circ}$ for $10 \mathrm{~min}$.

\subsection{SNP detection and genotyping}

The PCR-restriction fragment length polymorphism (PCRRFLP) technique was used to detect the polymorphisms of AGPAT6. The restriction enzyme digestion was performed in a total volume of $20 \mu \mathrm{L}$, and the restriction enzyme and the digestion reaction system of each SNP are presented in Table 2. The RFLP products for the SNPs of the AGPAT6 gene exon were detected by electrophoresis in a $4 \%$ agarose gel stained with ethidium bromide. The homozygotes were sequenced on an ABI PRISM 3100 genetic analyzer (Applied Biosystems, Foster City, CA, US) using dye terminators. The Basic Local Alignment Search Tool (BLAST) was used to assemble the sequences.

\subsection{Statistical analyses}

The allelic and genotypic frequencies of SNPS on the $A G$ PAT6 gene were calculated for the Simmental-cross steers and analyzed with tests of significance. The Hardy-Weinberg equilibrium of the polymorphism sites was determined with chi-squared $\left(\chi^{2}\right)$ tests using the SPSS statistical software package. The associations between the AGPAT6 gene polymorphisms and the meat quality traits or carcass traits were analyzed using two-way ANOVAs in SPSS 13.0 for Windows according to the following model:

$Y_{i j k}=u+y s_{i}+m_{j}+e_{i j k}$,

where $Y_{i j k}$ is the observed value of the $k$ th individual from the Simmental-cross breed of the genotype $j$ in the $i$ th yearseason; $u$ is the least-square mean of the observed values; $\mathrm{ys}_{i}$ is the effective value of the $i$ th year-season; $m_{j}$ is the effective value of genotype $j$; and $e_{i j k}$ is the random residual effect corresponding to the observed value.

\section{Results}

\subsection{PCR amplification}

The genomiDNA samples were harvested from 378 Simmental-cross cattle and amplified by two primers for the AGPAT6 gene. The PCR-amplified products conformed to the target fragments with good specificity and were directly analyzed using PCR-RFLP.

\subsection{RFLP analysis and sequencing of different genotypes}

The DNA sequencing and PCR-RFLP methods were used to detect variations in the bovine AGPAT6 gene. Two polymorphisms were identified: one in exon 1 and one in exon 12. A T/C substitution was found at position $303 \mathrm{bp}$ of the AGPAT6 gene exon 1, and it held four BstNI endonuclease restriction sites. Hence $411 \mathrm{bp}$ PCR products digested with BstNI showed four bands $(139,102,61$ and $48 \mathrm{bp})$ for the $\mathrm{T}$ allele and four bands $(163,139,61$ and $48 \mathrm{bp})$ for the $\mathrm{C}$ allele, and indicated TT, TC and CC genotypes. And a G/A substitution was found at position $299 \mathrm{bp}$ of the AGPAT6 gene exon 12, and it held two HhaI endonuclease restriction sites. Hence, 239 bp PCR products digested with HhaI showed two bands (119 and $58 \mathrm{bp)}$ ) for the GG genotype and three bands (177, 119 and 58 bp) for the AG genotype. The results are shown in Fig. 1. 
(a)

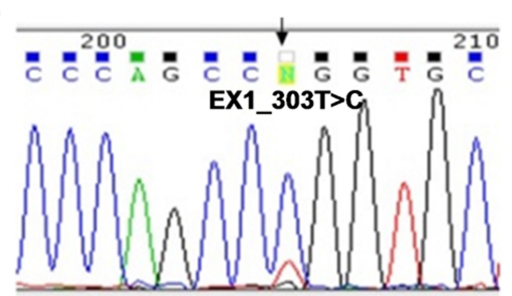

(c)

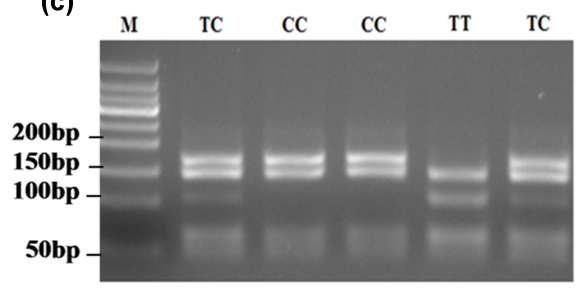

(b)

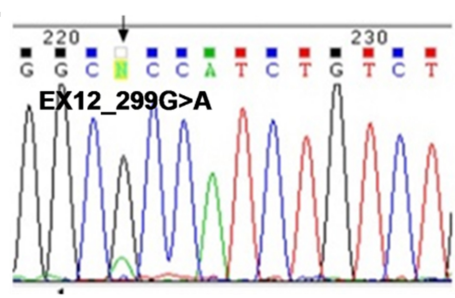

(d)

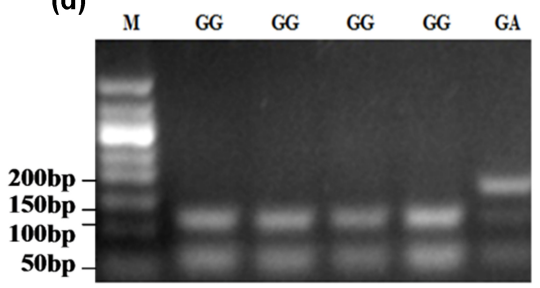

Figure 1. Sequencing and PCR-RFLP analysis of bovine AGPAT6 gene. (a) Sequencing maps of EX1_303T >C mutation position. (b) Sequencing maps of EX12_299G > A mutation position. (c) PCR-RFLP gel electrophoresis of EX1_303T >C mutation. (d) PCR-RFLP gel electrophoresis of EX12_299G > A mutation.

Table 3. Allele frequency and genotype frequency of the polymorphisms of the AGPAT6 gene.

\begin{tabular}{|c|c|c|c|c|c|c|}
\hline \multirow{2}{*}{$\begin{array}{l}\text { SNP location } \\
E X 1 \_303 T>C\end{array}$} & \multirow{2}{*}{$\begin{array}{c}\text { Number } \\
358\end{array}$} & \multicolumn{2}{|c|}{ Allele frequency } & \multicolumn{3}{|c|}{ Genotype frequency } \\
\hline & & (o 0051 & & & & \\
\hline EX12_299G $>A$ & 378 & $\mathrm{G}(0.9444)$ & $\mathrm{A}(0.0556)$ & GG (0.8889) & $\mathrm{AG}(0.1111)$ & $\mathrm{AA}(0.00)$ \\
\hline
\end{tabular}

\subsection{Genetic diversity of AGPAT6 gene in Chinese Simmental-cross cattle populations}

Table 3 shows the allele and genotype frequencies for the polymorphisms of the AGPAT6 gene. The frequency of allele $\mathrm{C}$ was 0.825 at the EX1_303T $>\mathrm{C}$ polymorphism site, and the frequency of allele $\mathrm{G}$ was 0.889 at the EX12_299G > A polymorphism site. The $\chi^{2}$ tests for the Hardy-Weinberg equilibrium of the two SNPs showed that the two SNPs of the AGPAT6 gene were in equilibrium.

\subsection{Association of AGPAT6 polymorphisms with the carcass and meat quality traits}

The statistical analyses revealed significant associations between the meat quality or the carcass traits and the SNPs in exons 1 and 12. The statistical results are shown below.

For cattle with the EX1_303T >C polymorphism site of the AGPAT6 gene, the individuals with the C-bearing genotypes (C-allele homozygotes or CT heterozygotes) had significantly lower liver weights, $\mathrm{pH}$ values of beef (carcass), fat coverage rates of carcasses and fat color scores than the TT genotype individuals. And the C-allele homozygotes showed higher kidney weight and back fat thickness than CT heterozygotes. Additionally, the omasum weight was the highest in the T-allele homozygotes, intermediate in the $\mathrm{C}$-allele homozygotes and lowest in the CT heterozygotes (Table 4, $p<0.05)$.
For cattle with the EX12_299G > A polymorphism site, the individuals with the AG genotype showed higher bone net weight, forehoof weight, hind feet weight and a higher fat coverage rate of the carcass than the individuals with the GG genotype. Furthermore, AG genotype individuals showed lower head and heart weights and marbling scores than GG genotype individuals (Table $4, p<0.05$ ).

\section{Discussion}

The cattle industry has primarily focused on optimizing the fat content of milk as well as the tenderness and flavor of meat. Several factors affect the production of these products, including the genetic background, management, nutrition and processing of cattle.

According to its sequence homology, AGPAT6 is one of the AGPAT isoforms (Nagle et al., 2008; Song et al., 2013). However, the identification of the GPAT activity of AGPAT6 showed that AGPAT6 is a novel microsomal GPAT (Chen et al., 2008). Moreover, the amino acid sequence of AGPAT6 is similar to both the AGPAT and GPAT sequences (Beigneux et al., 2006). GPAT and AGPAT catalyze the first and the second steps in the de novo synthesis of TG, respectively; in mammals, TG is the primary form of energy storage. Studies of mice have shown that AGPAT6 was highly expressed in brown adipose tissue and significantly affected the synthesis of TG in the brown adipose tissue and mammary gland 
Table 4. Assosiation of SNPs with carcass and meat quality traits in Simmental-cross steer.

\begin{tabular}{|c|c|c|c|c|c|c|c|c|c|c|c|c|c|c|c|}
\hline \multirow{3}{*}{ Traits } & \multicolumn{9}{|c|}{ Genotypes (EX1_303T > C) } & \multicolumn{6}{|c|}{ Genotypes (EX12_299G > A) } \\
\hline & \multicolumn{3}{|c|}{ TT } & \multicolumn{3}{|c|}{$\mathrm{CC}$} & \multicolumn{3}{|c|}{$\mathrm{TC}$} & \multicolumn{3}{|c|}{ AG } & \multicolumn{3}{|c|}{ GG } \\
\hline & $N$ & MEAN & SE & $N$ & MEAN & SE & $N$ & MEAN & SE & $N$ & MEAN & SE & $N$ & MEAN & SE \\
\hline NWB (kg) & 10 & 21.38 & 0.76 & 243 & 20.50 & 0.16 & 105 & 20.39 & 0.23 & 42 & $21.37^{\mathrm{a}}$ & 0.37 & 336 & $20.53^{b}$ & 0.14 \\
\hline HW1 (kg) & 10 & 23.42 & 0.42 & 243 & 23.74 & 0.09 & 105 & 23.63 & 0.13 & 42 & $23.46^{\mathrm{a}}$ & 0.20 & 336 & $23.87^{b}$ & 0.07 \\
\hline $\mathrm{FW}(\mathrm{kg})$ & 10 & 5.87 & 0.13 & 243 & 5.92 & 0.03 & 105 & 5.87 & 0.04 & 42 & $6.13^{\mathrm{a}}$ & 0.06 & 336 & $5.91^{\mathrm{b}}$ & 0.02 \\
\hline HFW (kg) & 10 & 3.86 & 0.11 & 243 & 3.82 & 0.02 & 105 & 3.81 & 0.04 & 42 & $3.97^{\mathrm{a}}$ & 0.06 & 336 & $3.82^{\mathrm{b}}$ & 0.02 \\
\hline HW2 (kg) & 10 & 1.68 & 0.06 & 243 & 1.75 & 0.01 & 105 & 1.77 & 0.02 & 42 & $1.70^{\mathrm{a}}$ & 0.03 & 336 & $1.76^{\mathrm{b}}$ & 0.01 \\
\hline OW (kg) & 10 & $4.34^{\mathrm{a}}$ & 0.16 & 243 & $4.17^{\mathrm{a}}$ & 0.03 & 105 & $3.98^{\mathrm{b}}$ & 0.05 & 42 & 4.18 & 0.08 & 336 & 4.12 & 0.03 \\
\hline LW (kg) & 10 & $6.00^{\mathrm{a}}$ & 0.17 & 243 & $5.65^{b}$ & 0.04 & 105 & $5.61^{b}$ & 0.05 & 42 & 5.78 & 0.09 & 336 & 5.64 & 0.03 \\
\hline KW (kg) & 10 & $1.08^{\mathrm{ab}}$ & 0.05 & 243 & $1.14^{\mathrm{a}}$ & 0.01 & 105 & $1.11^{\mathrm{b}}$ & 0.01 & 42 & 1.11 & 0.02 & 336 & 1.14 & 0.01 \\
\hline KFW (kg) & 10 & 3.16 & 0.47 & 243 & 4.05 & 0.10 & 105 & 3.92 & 0.15 & 42 & 4.03 & 0.24 & 336 & 4.05 & 0.09 \\
\hline GFW (kg) & 10 & 1.04 & 0.10 & 243 & 0.95 & 0.02 & 105 & 0.92 & 0.03 & 42 & 0.91 & 0.05 & 336 & 0.96 & 0.02 \\
\hline $\mathrm{CL}(\mathrm{cm})$ & 10 & 142.19 & 1.68 & 243 & 141.44 & 0.35 & 105 & 142.10 & 0.52 & 42 & 142.03 & 0.81 & 336 & 141.88 & 0.30 \\
\hline $\mathrm{TL}(\mathrm{cm})$ & 10 & 6.38 & 0.18 & 243 & 6.70 & 0.04 & 105 & 6.67 & 0.06 & 42 & 6.790 & 0.09 & 336 & 6.68 & 0.03 \\
\hline BFT (cm) & 10 & $0.80^{\mathrm{ab}}$ & 0.12 & 243 & $0.84^{\mathrm{a}}$ & 0.03 & 105 & $0.75^{\mathrm{b}}$ & 0.04 & 42 & 0.86 & 0.06 & 336 & 0.79 & 0.02 \\
\hline $\operatorname{REA}\left(\mathrm{cm}^{2}\right)$ & 10 & 75.44 & 3.20 & 243 & 77.96 & 0.68 & 105 & 77.15 & 0.99 & 42 & 79.13 & 1.58 & 336 & 77.80 & 0.58 \\
\hline $\mathrm{pH}$ & 10 & $6.41^{\mathrm{a}}$ & 0.10 & 243 & $6.42^{\mathrm{b}}$ & 0.02 & 105 & $6.33^{\mathrm{b}}$ & 0.03 & 42 & 6.46 & 0.05 & 336 & 6.38 & 0.02 \\
\hline FCR $(\%)$ & 10 & $44.11^{\mathrm{a}}$ & 3.10 & 243 & $41.51^{b}$ & 0.65 & 105 & $43.11^{\mathrm{b}}$ & 0.96 & 42 & $45.66^{\mathrm{a}}$ & 1.47 & 336 & $42.14^{\mathrm{b}}$ & 0.54 \\
\hline MBS & 10 & 5.62 & 0.19 & 243 & 5.48 & 0.04 & 105 & 5.56 & 0.06 & 42 & $5.31^{\mathrm{a}}$ & 0.09 & 336 & $5.51^{\mathrm{b}}$ & 0.03 \\
\hline MCS & 10 & 5.50 & 0.31 & 243 & 5.42 & 0.06 & 105 & 5.53 & 0.09 & 42 & 5.38 & 0.15 & 336 & 5.49 & 0.05 \\
\hline FCS & 10 & $3.18^{\mathrm{a}}$ & 0.25 & 243 & $2.92^{\mathrm{b}}$ & 0.05 & 105 & $2.86^{\mathrm{b}}$ & 0.08 & 42 & 2.98 & 0.12 & 336 & 2.92 & 0.04 \\
\hline
\end{tabular}

epithelial cells. Additionally, the protein subcellular location showed that AGPAT6 was expressed within the endoplasmic reticulum (Beigneux et al., 2006). The absence of AGPAT6 resulted in poor mammary gland development and inadequate diglyceride and TG contents in milk (Littlejohn et al., 2014). In HEK293 cells, the overexpression of AGPAT6 increased the contents of both LPA and PA, as determined by ${ }^{13} \mathrm{C}_{7}$ labeling and mass spectrometry (Chen et al., 2008). In contrast, the LPA and PA contents decreased by 80 and $64 \%$, respectively, when AGPAT6 was knocked out in mouse mammary gland membranes (Vergnes et al., 2006).

Several SNPs in the AGPAT6 gene were also identified in other species. In Holstein cattle, two SNPs, which were significantly associated with milk yield and fat content, were identified in intron 3 of AGPAT6. An SNP that was significantly associated with milk yield and the protein and fat contents was also identified in intron 2. A $\mathrm{C}>\mathrm{G}$ mutation was detected in exon 4 of the dairy goat AGPAT6 gene, and this mutation also resulted in a significant difference in milk yield and the protein and fat contents.

In the present study, the AGPAT6 gene EX1_303T >C SNP was significantly associated with the meat quality and carcass traits. The omasum was heaviest in the T-allele homozygotes, followed by the C-allele homozygotes and the CT heterozygotes, whose omasa were lightest. The C-allele homozygotes and CT-allele heterozygotes both had lower liver weights, beef $\mathrm{pH}$ values (carcass), carcass fat coverage rates and fat color scores than T-allele homozygotes. Addi- tionally, the CC genotype was significantly associated with a high kidney weight and high back fat thickness.

The associations between the AGPAT6 gene EX12_299G > A SNP and the meat quality and carcass traits in the Simmental-cross steers were also analyzed. The AG genotype had higher bone, forehoof and hind feet net weights and higher fat coverage rates of the carcasses than the other genotypes. Conversely, the head and heart weights and marbling scores of the AG genotype were lower than those of the other genotypes.

The omasum, liver, kidney and heart are the edible parts of the body; a heavier weight is better. The bone, forehoof, hind feet and the head of fattening steer are the inedible parts; a lighter weight is better. The fat coverage rate of the carcass, back fat thickness and the marbling score influence the flavor and taste of beef. Higher values here are better for the breeding and production of beef cattle. In this study, the tested SNPs were associated with the fat coverage rate of the carcass, fat color score, back fat thickness and marbling score. These traits were associated with the lipin metabolism. Previous studies found that changes in AGPAT6 expression levels influenced the TG content and that the SNPs had significant effects on fat contents. The results showed that AGPAT6 might be influenced by lipin metabolism.

Therefore, this study contributed to the evaluation of $A G$ PAT6 as a genetic marker for Simmental-cross steer breeding strategies, although further studies are required to determine 
whether AGPAT6 is a candidate gene to enhance traits of economic interest in beef cattle.

Acknowledgements. This work was supported by the $\mathrm{Na}$ tional High Technology Research and Development Program (863 Program, no.2013AA102505), the Jilin province industrial technology research and development program (2016C032), the National Natural Science Foundation of China (no. 31372278), and the National R\&D Project of Transgenic Organisms of the Ministry of Science and Technology of China (2013ZX08007-001).

Edited by: S. Maak

Reviewed by: two anonymous referees

\section{References}

Agarwal, A. K. and Garg, A.: Enzymatic activity of the human 1acylglycerol-3-phosphate-O- acyltransferase isoform 11: upregulated in breast and cervical cancers, J. Lipid Res., 51, 21432152, doi:10.1194/jlr.M004762, 2010.

Agarwal, A. K., Barnes, R. I., and Garg, A.: Functional characterization of human 1-acylglycerol-3- phosphate acyltransferase isoform 8: cloning, tissue distribution, gene structure, and enzymatic activity, Arch. Biochem. Biophys., 449, 64-76, doi:10.1016/j.abb.2006.03.014, 2006.

Agarwal, A. K., Sukumaran, S., Bartz, R., Barnes, R. I., and Garg, A.: Functional characterization of human 1-acylglycerol3-phosphate-O-acyltransferase isoform 9: cloning, tissue distribution, gene structure, and enzymatic activity, J. Endocrinol., 193, 445-457, doi:10.1677/JOE-07-0027, 2007.

Aguado, B. and Campbell, R. D.: Characterization of a human lysophosphatidic acid acyltransferase that is encoded by a gene located in the class III region of the human major histocompatibility complex, J. Biol. Chem., 273, 4096-4105, 1998.

Beigneux, A. P., Vergnes, L., Qiao, X., Quatela, S., Davis, R., Watkins, S. M., Coleman, R. A., Walzem, R. L., Philips, M., Reue, K., and Young, S. G.: Agpat6-a novel lipid biosynthetic gene required for triacylglycerol production in mammary epithelium, J. Lipid Res., 47, 734-744, doi:10.1194/jlr.M500556JLR200, 2006.

Chen, Y. Q., Kuo, M. S., Li, S., Bui, H. H., Peake, D. A., Sanders, P. E., Thibodeaux, S. J., Chu, S., Qian, Y. W., Zhao, Y., Bredt, D. S., Moller, D. E., Konrad, R. J., Beigneux, A. P., Young, S. G., and Cao, G.: AGPAT6 is a novel microsomal glycerol3-phosphate acyltransferase, J. Biol. Chem., 283, 10048-10057, doi:10.1074/jbc.M708151200, 2008.

Eberhardt, C., Gray, P. W., and Tjoelker, L. W.: Human lysophosphatidic acid acyltransferase. cDNA cloning, expression, and localization to chromosome 9q34.3, J. Biol. Chem., 272, 2029920305, 1997.

Gimeno, R. E. and Cao, J.: Thematic review series: Glycerolipids - Mammalian glycerol-3-phosphate acyltransferases: new genes for an old activity, J. Lipid Res., 49, 2079-2088, doi:10.1194/jlr.R800013-JLR200, 2008.

Gonzalez-Baro, M. R., Lewin, T. M., and Coleman, R. A.: Regulation of Triglyceride Metabolism. II. Function of mitochondrial GPAT1 in the regulation of triacylglycerol biosynthesis and insulin action, Am. J. Physiol.-Gastr. L., 292, G1195-1199, doi:10.1152/ajpgi.00553.2006, 2007.

He, C., Wang, C., Chang, Z. H., Guo, B. L., Li, R., Yue, X. P., Lan, X. Y., Chen, H., and Lei, C. Z.: AGPAT6 polymorphism and its association with milk traits of dairy goats, Genet. Mol. Res., 10, 2747-2756, doi:10.4238/2011.November.4.8, 2011.

Leung, D. W.: The structure and functions of human lysophosphatidic acid acyltransferases, Front. Biosci., 6, D944-D953, doi:10.2741/Leung, 2001.

Liebisch, G., Lieser, B., Rathenberg, J., Drobnik, W., and Schmitz, G.: High-throughput quantification of phosphatidylcholine and sphingomyelin by electrospray ionization tandem mass spectrometry coupled with isotope correction algorithm, Biochim. Biophys. Acta, 1686, 108-117, doi:10.1016/j.bbalip.2004.09.003, 2004.

Littlejohn, M. D., Tiplady, K., Lopdell, T., Law, T. A., Scott, A., Harland, C., Sherlock, R., Henty, K., Obolonkin, V., Lehnert, K., Macgibbon, A., Spelman, R. J., Davis, S. R., and Snell, R. G.: Expression variants of the lipogenic AGPAT6 gene affect diverse milk composition phenotypes in Bos taurus, PLoS One, 9, e85757, doi:10.1371/journal.pone.0085757, 2014.

Monziols, M., Bonneau, M., Davenel, A., and Kouba, M.: Comparison of the lipid content and fatty acid composition of intermuscular and subcutaneous adipose tissues in pig carcasses, Meat. Sci., 76, 54-60, doi:10.1016/j.meatsci.2006.10.013, 2007.

Nagle, C. A., Vergnes, L., Dejong, H., Wang, S., Lewin, T. M., Reue, K., and Coleman, R. A.: Identification of a novel snglycerol-3-phosphate acyltransferase isoform, GPAT4, as the enzyme deficient in Agpat6-/- mice, J. Lipid Res., 49, 823-831, doi:10.1194/jlr.M700592-JLR200, 2008.

Prasad, S. S., Garg, A., and Agarwal, A. K.: Enzymatic activities of the human AGPAT isoform 3 and isoform 5: localization of AGPAT5 to mitochondria, J. Lipid Res., 52, 451-462, doi:10.1194/jlr.M007575, 2011.

Song, S., Huo, J. L., Li, D. L., Yuan, Y. Y., Yuan, F., and Miao, Y. W.: Molecular cloning, sequence characterization, and gene expression profiling of a novel water buffalo (Bubalus bubalis) gene, AGPAT6, Genet. Mol. Res., 12, 4116-4126, doi:10.4238/2013.October.1.2, 2013.

Sukumaran, S., Barnes, R. I., Garg, A., and Agarwal, A. K.: Functional characterization of the human 1-acylglycerol3-phosphate-O-acyltransferase isoform 10/glycerol-3-phosphate acyltransferase isoform 3, J. Mol. Endocrinol., 42, 469-478, doi:10.1677/JME-09-0010, 2009.

Takeuchi, K. and Reue, K.: Biochemistry, physiology, and genetics of GPAT, AGPAT, and lipin enzymes in triglyceride synthesis, Am. J. Physiol.-Endoc. M., 296, E1195-1209, doi:10.1152/ajpendo.90958.2008, 2009.

Vergnes, L., Beigneux, A. P., Davis, R., Watkins, S. M., Young, S. G., and Reue, K.: Agpat6 deficiency causes subdermal lipodystrophy and resistance to obesity, J. Lipid Res., 47, 745-754, doi:10.1194/jlr.M500553-JLR200, 2006.

Wendel, A. A., Cooper, D. E., Ilkayeva, O. R., Muoio, D. M., and Coleman, R. A.: Glycerol-3-phosphate acyltransferase (GPAT)1 , but not GPAT4, incorporates newly synthesized fatty acids into triacylglycerol and diminishes fatty acid oxidation, J. Biol. Chem., 288, 27299-27306, doi:10.1074/jbc.M113.485219, 2013. 
Ye, G. M., Chen, C., Huang, S., Han, D. D., Guo, J. H., Wan, B., and $\mathrm{Yu}, \mathrm{L}$.: Cloning and characterization a novel human 1-acyl-snglycerol-3-phosphate acyltransferase gene AGPAT7, DNA Sequence, 16, 386-390, doi:10.1080/10425170500213712, 2005. 